\title{
Efeito da técnica de curtimento e do método utilizado para remoção da pele da tilápia-do-nilo sobre as características de resistência do couro
}

\author{
Maria Luiza Rodrigues de Souza ${ }^{1}$, Jorge de Matos Casaca ${ }^{2}$, Laura Satiko Okada Nakaghi ${ }^{3}$, \\ Nilson do Prado Franco ${ }^{2}$, Leocília Oliveira da Silva ${ }^{4}$, Doroty Mesquita Dourado ${ }^{5}$, Elisabete \\ Maria Macedo Viegas ${ }^{6}$
}

\footnotetext{
${ }^{1}$ Depto de Zootecnia - Universidade Estadual de Maringá. Av. Colombo 5790, CEP: 87020-900, Maringá - PR, Brasil.

2 Pós-graduação em Aqüicultura - CAUNESP - Jaboticabal - SP.

${ }^{3}$ Depto de Morfologia e Fisiologia Animal da FCAVIUNESP - Jaboticabal - SP.

${ }^{4}$ Biológa.

5 Centro de Ciências Biológicas, Agrárias e da Saúde da Universidade para o Desenvolvimento do Estado e da Região do Pantanal (UNIDERP).

${ }^{6}$ Depto de Zootecnia/FZEA-USP e CAUNESP/Jaboticabal. Av. Duque de Caxias Norte, 225, CEP: 13635-900, Pirassununga - SP.

Apoio: Secretaria Especial de Aqüicultura e Pesca da Presidência da República.
}

RESUMO - Um estudo foi realizado com o objetivo de avaliar os efeitos do método de remoção da pele do filé (com alicate e com máquina) e da técnica de curtimento (com ou sem sais de cromo, bioleather) sobre a resistência da pele de tilápia-donilo (Oreochromis niloticus). Foram retiradas as peles de 40 tilápias (450 g), $20 \mathrm{com}$ uso de alicates e 20 com auxílio de máquina Após o curtimento e a retirada dos corpos-de-prova, as peles foram encaminhadas a um laboratório aclimatizado $\left(23^{\circ} \mathrm{C}\right.$ e $50 \%$ de umidade relativa do ar) para realização dos testes de resistência em dinamômetro EMIC, com velocidade de afastamento entre cargas de $100 \pm 20 \mathrm{~mm} / \mathrm{mm}$. O método de retirada da pele do filé não afetou os resultados dos testes de tração e rasgamento progressivo. A pele retirada com a máquina apresentou elongação superior $(88,48 \%)$ à removida com alicate $(71,09 \%)$. Peles curtidas com sais de cromo $\left(25,54 \mathrm{~N} / \mathrm{mm} ; 12,18 \mathrm{~N} / \mathrm{mm}^{2}\right)$ foram mais resistentes que as curtidas sem sais de cromo (bioleather) $\left(13,11 \mathrm{~N} / \mathrm{mm} ; 9,89 \mathrm{~N} / \mathrm{mm}^{2}\right.$ ). Peles curtidas por estas técnicas (com cromo e bioleather) podem ser utilizadas na confecção de vestuários, pois as médias dos testes de tração, alongamento e rasgamento progressivo foram superiores a $9,80 \mathrm{~N} / \mathrm{mm}^{2}$, $60 \%$ e $14,72 \mathrm{~N} / \mathrm{mm}$, respectivamente, valores mínimos recomendados para couros curtidos ao cromo.

Palavras-chave: pele ecológica, qualidade da pele, retirada da pele do filé, testes físicos-mecânicos

\section{Effect of tanning technique and methods used for skin removal on leather resistance characteristics of Nile Tilapia}

\begin{abstract}
This research evaluated the effect of different methods (fillet skin removal and tanning methods [with or without chromium salts and bioleather]) on leather resistance characteristics of Nile Tilapia (Oreochromis niloticus). Skin from 40 tilapias $(450 \mathrm{~g}$ ) were removed: 20 by pliers and 20 by machine. After skin tanning, the samples were removed for resistance tests, which were done, in a climatized environment $\left(23^{\circ} \mathrm{C}\right)$ and $50 \%$ air relative humidity, with EMIC dynamometer, at removal speed of $100 \pm 20 \mathrm{~mm} / \mathrm{mm}$. No effect of fillet skin removal method on progressive tearing and strength was observed The method of skin removal by machine resulted in greater $(88.48 \%)$ elongation than that removed by pliers $(71.09 \%)$. Skin tanned with chromium salts $\left(25.54 \mathrm{~N} / \mathrm{mm} ; 12.18 \mathrm{~N} / \mathrm{mm}^{2}\right)$ had higher resistance than that tanned without chromium (bioleather) $\left(13.11 \mathrm{~N} / \mathrm{mm} ; 9.89 \mathrm{~N} / \mathrm{mm}^{2}\right)$. Chromium- and bioleather tanned skins may be used in clothes manufacture since average values of strength, elongation and progresive tearing are higher than $9.80 \mathrm{~N} / \mathrm{mm}^{2}, 60 \%$ and $14.72 \mathrm{~N} / \mathrm{mm}$, respectively, which are values recommended for leathers tanned with chromium salts.
\end{abstract}

Key Words: bioleather skin, fillet skin removal, physical and mechanical tests, skin quality, skin resistance

\section{Introdução}

Com a intensificação da piscicultura e com a tendência de algumas empresas brasileiras exportarem o filé de peixe sem pele, as peles de peixes são descartadas ou direcionadas, junto com os demais resíduos, à produção de farinha ou silagem de peixe. Todavia, o processo de curti- mento das peles pode ser uma forma de agregar valor a um resíduo que, de outra forma, seria descartado. A unidade curtida hoje atinge $\mathrm{R} \$ 1,00$ a $\mathrm{R} \$ 2,50$ conforme o tamanho e a forma de acabamento.

Com essa ampliação na comercialização, alternativas para maior produção na linha de processamento do peixe tornam-se extremamente importantes. Uma das formas viá- 
veis seria a adequação na linha de filetagem, utilizando-se equipamentos regulados, para alta produção em curto prazo, como ocorre quando a retirada da pele dos filés é realizada com máquina apropriada.

A pele é um subproduto que pode ter elevado valor econômico com o processo de curtimento (Souza, 2004). Porém, é importante que esse processo seja realizado de forma a não agredir o meio ambiente. Atualmente, tem-se valorizado a produção do "couro ecológico", buscando alternativas para processamento da pele com produtos mais naturais, direcionando a atenção dos produtores para um futuro em que se possa dispensar o uso de sais de cromo. Portanto, de acordo com o CATC-BASF (1999), deve-se dar atenção especial ao "wet-white" a partir do uso de dialdeído glutárico, ponto de partida mais generalizado e aprovado para os "couros ecológicos" ou o "couro bioleather".

O impacto ambiental é um fator muito discutido em qualquer área da produção, tanto na aqüicultura, agricultura e pecuária quanto na atividade industrial, como os curtumes. Buscam-se, portanto, alternativas tecnológicas para substituição do cromo por outros agentes de curtimento (curtentes vegetais, sais minerais alternativos, compostos orgânicos reativos e substituição parcial do cromo pela obtenção de wet-white), bem como a otimização no processo de curtimento ao cromo, utilizando-se métodos de autoesgotamento de cromo, de sistemas de re-ciclos e outros (Gutterres, 1997).

As atuais manifestações ecológicas estimularam novos segmentos de mercado a aderirem ao "couro ecológico", muito mais importante para uso em artefatos que não exigem determinadas resistências físicas, como estabilidade em temperaturas de $100^{\circ} \mathrm{C}$ ou mais (Souza, 2004). Na confecção de estofamento, não existe esse problema e couros "livres de cromo", elaborados a partir de "wetwhite", são consumidos em larga escala pela indústria automobilística, especialmente os Dialdeído Glutárico (CATC-BASF, 1999).

Graffunder \& Kolling (2002) citam resinas recurtentes como um avanço técnico e ecológico para proporcionar tecnologia limpa no curtimento de couros. Os compostos recurtentes apresentam elevada solidez à luz e ao calor e promovem enchimento ao couro sem prejuízo à maciez, além de melhora significativa na resistência ao rasgamento progressivo.

Neste sentido, este estudo foi realizado com o objetivo de avaliar o efeito do método de retirada da pele do filé e da técnica de curtimento aplicada (com ou sem sais de cromo -bioleather) sobre a resistência e a qualidade do couro da tilápia-do-nilo (Oreochromis niloticus).

\section{Material e Métodos}

Os ensaios foram realizados no Laboratório de Curtimento da Universidade Estadual de Maringá (Maringá-PR) e os testes físico-químicos, na BASF, Empresa Multinacional produtora e fornecedora de insumos químicos para a indústria de curtimento.

Quarenta tilápias-do-nilo de aproximadamente $450 \mathrm{~g}$ foram abatidas por choque térmico (água e gelo na proporção 1:1) para retirada da pele e do filé. Em 20 tilápias, primeiramente retirou-se a pele (com auxílio de alicate) e, em seguida, o filé (M1). Nas demais, retirou-se o filé e, em seguida, a pele, utilizando-se máquina apropriada (M2). As peles foram identificadas individualmente com miçangas (fixadas com linha mercê $n^{\circ} 40$ ) e distribuídas aleatoriamente em dois fulões (equipamento de formato cilíndrico, apresentando nas paredes internas travessas ou tornos destinados a favorecer a movimentação da carga), com velocidade de rotação $16 \mathrm{rpm} / \mathrm{min}$. Em um fulão, foram colocadas 20 peles retiradas com uso de alicate e 20 retiradas com máquina, para curtimento pela técnica com sais de cromo. No outro fulão, distribuíram-se as outras 20 peles retiradas com alicate e as 20 extraídas com máquina, para curtimento pela técnica sem sais de cromo ou bioleather (à base de sulfona e ácidos sulfônicos aromáticos, composta por taninos fenólicos, aldeído glutárico e cloreto básico de alumínio). Nas Figuras 1A e B são descritas as duas técnicas de curtimento.

Após o curtimento das peles, foram retirados dez corposde-prova no sentido longitudinal ao comprimento do corpo do peixe, para determinação da resistência à tração, ao alongamento (ABNT - NBR 11041, 1997) e ao rasgamento progressivo (ABNT - NBR 11055, 1997) (Figura 2). Como não existem normas específicas para realização dos testes de resistência dos couros de peixes, foram estabelecidos determinados parâmetros para retirada dos corpos-de-prova, incluindo local, posição e número de amostragens.

Os corpos-de-prova foram retirados do couro (ABNT - NBR 11035, 1990) com uso de um balancim. Em seguida, foram encaminhados a um laboratório climatizado $\left(23^{\circ} \mathrm{C}\right.$ e $50 \%$ de umidade relativa do ar) por 24 horas, conforme ABNT (NBR 10455, 1988), e determinadas as espessuras de cada amostra (ABNT - NBR 11062, 1997). Para os testes de resistência, foi utilizado dinamômetro EMIC com velocidade de afastamento entre cargas de $100 \pm 20 \mathrm{~mm} / \mathrm{mm}$.

A preparação de amostras de couro para análise química foi realizada de acordo com as condições exigidas pelas normas da ABNT (NBR 11034, 2001), para determinação do óxido de cromo $\mathrm{Cr}_{2} \mathrm{O}_{3}$ (ABNT - NBR 11054, 1999), das substâncias extraíveis com diclorometano $\left(\mathrm{CH}_{2} \mathrm{Cl}_{2}\right)(\mathrm{ABNT}$ 


\section{A. Sais de cromo}

\begin{tabular}{|c|c|c|c|c|}
\hline$\%$ & Produtos & npo (min) & Obs: & $\mathrm{pH}$ \\
\hline \multicolumn{5}{|c|}{ Remolho } \\
\hline 200 & Água $25^{\circ} \mathrm{C}$ & & & \\
\hline 0,4 & Tensoativo $^{1}$ & 20 & Esgotar/lavar 15, & \\
\hline \multicolumn{5}{|c|}{ Caleiro } \\
\hline 200 & Água $25^{\circ} \mathrm{C}$ & & & \\
\hline 2,5 & Sulfeto de sódio & & & \\
\hline 2,5 & Cal hidratada & & & \\
\hline 0,3 & Tensoativo $^{1}$ & 120 & Esgotar & \\
\hline \multicolumn{5}{|c|}{ Desencalagem } \\
\hline 100 & Água $25^{\circ} \mathrm{C}$ & & & \\
\hline 2 & Sulfato de amônio & 20 & Esgotar & 9 \\
\hline \multicolumn{5}{|c|}{ Purga } \\
\hline 100 & Água $25^{\circ} \mathrm{C}$ & & & \\
\hline 0,05 & Enzima pancreática ${ }^{2}$ & 60 & & \\
\hline 1,5 & Sulfato de amônio & 20 & Esgotar e lavar & \\
\hline 100 & Água $25^{\circ} \mathrm{C}$ & & & \\
\hline 0,05 & Enzima pancreática $^{2}$ & 60 & & \\
\hline 0,2 & Desencalante 3 & - & & \\
\hline 2 & Sulfato de amônio & 20 & & \\
\hline 0,3 & Tensoativo $^{1}$ & 20 & Esgotar e lavar & \\
\hline
\end{tabular}

Píquel e curtimento

\begin{tabular}{|c|c|c|c|c|}
\hline 100 & Água $25^{\circ} \mathrm{C}$ & & & \\
\hline 14 & Sal grosso & 15 & $8^{\circ} \mathrm{Bé}$ & \\
\hline 0,9 & Ácido sulfúrico & $3 \times 15-120$ & & 3,5 \\
\hline 8 & Sais de cromo & 50 & & \\
\hline 2 & Bicarbonato de sódio & & $3 \times 15$ & 3,9 \\
\hline & & Pernoitar & & \\
\hline Neut & zação & & & \\
\hline 100 & Água $25^{\circ} \mathrm{C}$ & & & \\
\hline 0,7 & Neutralizante ${ }^{8}$ & 10 & & \\
\hline 0,5 & Bicarbonato de sódio & $3 \times 15$ & & \\
\hline 0,7 & Formiato de sódio & 30 & & 5,7 \\
\hline & & & Esgotar/lavar & \\
\hline Recu & ento, tingimento e en & ngraxe & & \\
\hline 50 & Água $25^{\circ} \mathrm{C}$ & & & \\
\hline 3 & Hidrofugante ${ }^{10}$ & & & \\
\hline 1 & Hidrofugante ${ }^{11}$ & & & \\
\hline 0,1 & Hidrofugante ${ }^{12}$ & 40 & & \\
\hline 1,5 & $\begin{array}{c}\text { Tanino de acácia } \\
\text { (mimosa) } \\
\text { Conc. } 95 \%\end{array}$ & & & \\
\hline 1,5 & Taninos de quebracho & & & \\
\hline & -adstringente. Conc. & $95 \%$ & & \\
\hline 1,5 & Curtente ${ }^{8}$ & 30 & & \\
\hline 3 & Corante vermelho & 60 & & \\
\hline 200 & Água $60^{\circ} \mathrm{C}$ & & & \\
\hline 2 & Ácido fórmico & $2 \times 15$ & Esgotar & 3,4 \\
\hline Engr & & & & \\
\hline 200 & Água $60^{\circ} \mathrm{C}$ & & & \\
\hline 3 & Hidrofugante ${ }^{10}$ & $2 \times 15$ & Esgotar & 3,5 \\
\hline 1 & Hidrofugante ${ }^{11}$ & 60 & & \\
\hline 1 & Ácido fórmico & 20 & & \\
\hline 1,5 & Sais de cromo & 30 & & \\
\hline 1 & Ácido fórmico & 20 & Esgotar & \\
\hline 50 & Água $30^{\circ} \mathrm{C}$ & & & \\
\hline 1 & Sais de cromo & 30 & & \\
\hline 2 & Sais de cromo & 60 & Esgotar/lavar & \\
\hline
\end{tabular}

B. Sem sais de cromo - Bioleather

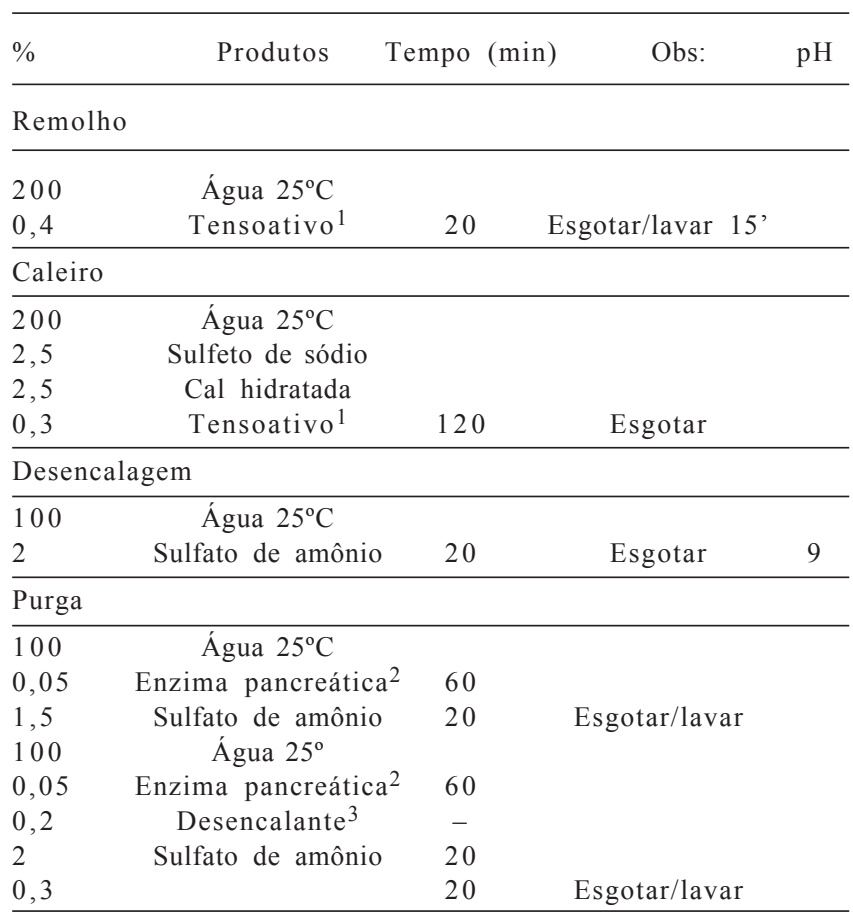

Píquel e curtimento

\begin{tabular}{lcccc}
\hline 100 & Água $25^{\circ} \mathrm{C}$ & & \\
14 & Sal grosso & 15 & $8^{\circ}$ Bé & \\
0,45 & Ácido sulfúrico & $3 \times 15$ & & \\
1,7 & Ácido fórmico & $3 \times 15$ & 120 & 3,6 \\
0,5 & $\quad$ Óleo ${ }^{4}$ & & & \\
4 & Curtente $^{5}$ & 50 & & \\
2,5 & Neutralizante & 5 & \\
1 & $\quad$ Curtente & & \\
1 & Formiato de sódio & 60 & & \\
1,5 & $\quad$ Curtente $^{8}$ & 60 & Esgotar & \\
\hline Neutralização & & & \\
\hline 150 & $\quad$ Água $30^{\circ} \mathrm{C}$ \\
0,7 & Neutralizante & & \\
0,5 & Bicarbonato de sódio $2 \times 15+30$ & Esgotar/lavar & 6,9
\end{tabular}

Recurtimento, tingimento e engraxe

\begin{tabular}{lll}
\hline 50 & ${\text { Água } 30^{\circ}}$ & \\
3 & Hidrofugante $^{10}$ & \\
1 & Hidrofugante $^{11}$ & \\
0,1 & Hidrofugante $^{12}$ & 30 \\
4 & Curtente $^{8}$ & 20 \\
4 & Curtente $^{8}$ & 20 \\
\hline
\end{tabular}

1 Tensoativo - compostos orgânicos surfactantes iônicos e não-iônicos. Concentração $82 \%$;

2 Enzima pancreática com 10.000 UFG

3 Desencalante - mistura ac. Orgânicos e inorgânicos isentos de nitrogênio. 4 Óleo - mistura de óleo sintético e natural (lecitina) predominando óleo sintético. Concen-

5 Curtente - aldeído glutárico + polímero acrílico. Concentração $95 \%$.

6 Neutralizante à base de curtente sintético e ácidos orgânicos. Concentração $95 \%$.

7 Curtente produto de condensação à base de sulfona e ácidos sulfônicos aromáticos. Concentração $40 \%, \mathrm{pH} 4(1: 10)$.

8 Curtente de substituição, à base de condensação de fenol (fenólico ). Concentração $9 \%$

9 NH $3,3(1: 10)$.

10 Heutralizante à base de sulfitos, formiato e ftalato de sódio. Concentração $45 \%$ pH 8,5 (1:10).

11 Hidrofugante-engraxante sintético contendo silicone dotado de um sistema emulsionante especial. Concentração $50 \%$ pH $8(1: 10)$.

12 Hidrofugante - solução polimérica aquosa aniônica isenta de AOX. Concentração $40 \%$. $\mathrm{pH} 7,5(1: 10)$.

13 Curtente à base de alumínio - cloreto básico de alumínio. Concentração de $\mathrm{Al}_{2} \mathrm{O}_{3} 17 \%$ basicidade $66 \% \mathrm{pH} 3,5(1: 10)$.

Figura 1 - Formulação com sais de cromo (A) e sem sais de cromo - Bioleather (B). 


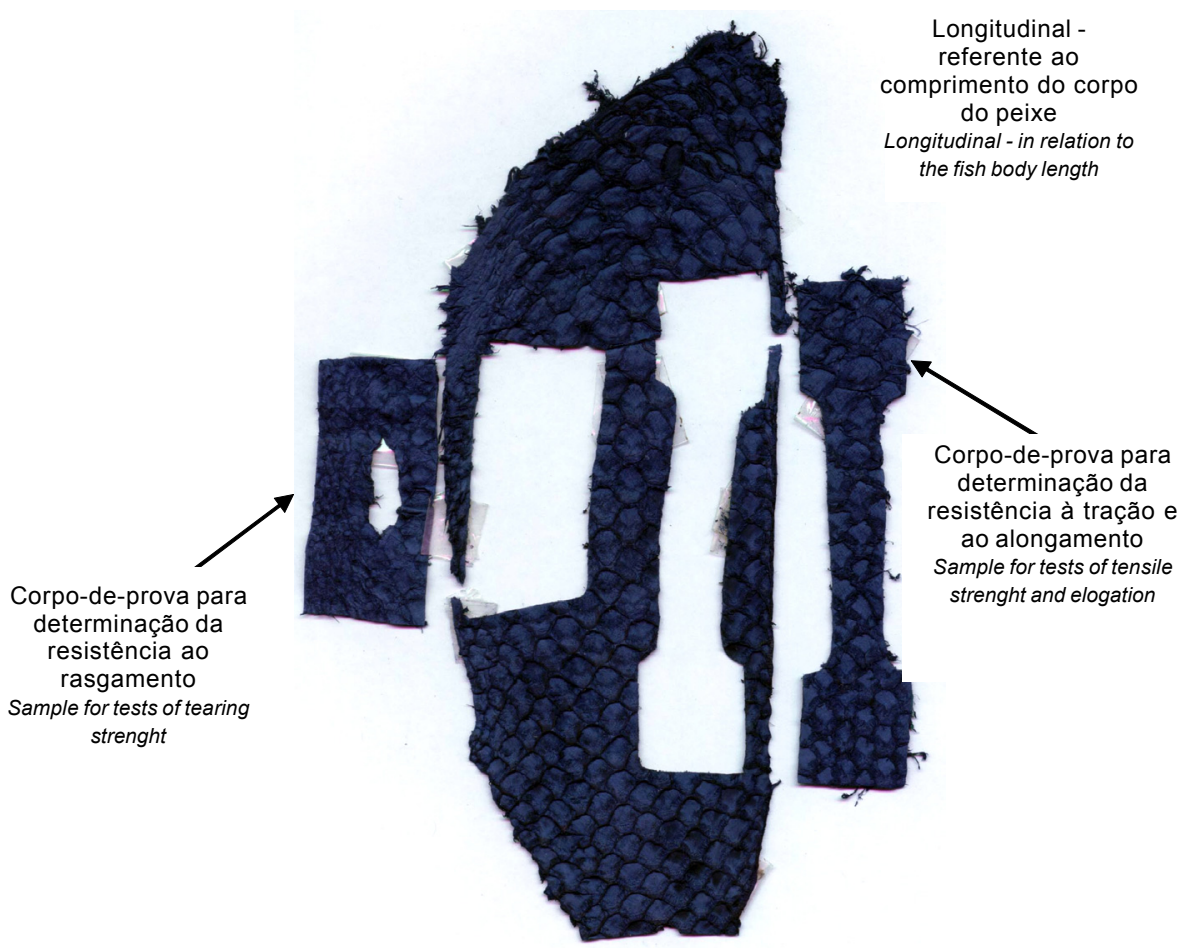

Figura 2 - Retirada dos corpos-de-prova do couro de tilápia-do-nilo (Oreochromis niloticus) no sentido longitudinal ao comprimento do corpo do peixe.

Figure 2 - Leather samples removal of Nile Tilapia (Oreochromis niloticus) hide longitudinal direction to the body length.

- NBR 11030, 1997), do pH e da cifra diferencial do $\mathrm{pH}$ de um extrato aquoso (ABNT- NBR 11057, 1999).

O delineamento experimental adotado foi o inteiramente casualizado, em esquema fatorial $2 \times 2$, dois métodos de retirada da pele do filé (com alicate e com a máquina) e duas técnicas de curtimento (com e sem sais de cromo bioleather), considerando o couro a unidade experimental.

Os resultados dos testes físico-mecânicos foram submetidos à análise de variância, comparando-se as médias pelo teste Tukey a 5\% de probabilidade (Banzatto \& Kronka, 1995).

Os resultados dos testes físico-químicos foram utilizados apenas para caracterização do produto final (couro).

\section{Resultados e Discussão}

O método de retirada da pele (alicate ou máquina) influenciou a porcentagem de pele, calculada em relação ao peso do peixe inteiro. Quando retirada com alicate, a porcentagem de pele de tilápia-do-nilo foi significativamente ( $\mathrm{P}<0,01)$ inferior (6,54 vs 7,64\% - com máquina).

A diferença quanto ao método de retirada da pele do filé demonstra que maior quantidade de musculatura do filé ficou retida na pele quando se fez a retirada com máquina, o que dificulta o processo de curtimento, por haver neces- sidade de mais mão-de-obra para a execução do descarne (remoção do músculo da pele). Souza et al. (1999) analisaram a influência do método de filetagem e das categorias de peso sobre o rendimento de carcaça, filé e pele de tilápia-do-nilo e constataram que, em peixes de 250 a $450 \mathrm{~g}$, quando a pele foi retirada com alicate $(5,32 \%)$, a porcentagem de pele foi menor que quando retirada com faca $(8,51 \%)$. Os autores afirmaram que a porcentagem de descarne foi maior para as peles retiradas com faca. Portanto, na pele retirada com alicate, a porcentagem de pele é sempre menor que naquelas retiradas com faca ou máquina, visto que menor quantidade de músculos permanece na pele. Portanto, quanto menor a proporção de músculo na pele após retirada do filé mais rapidamente será descarnada, necessitando de menos mãode-obra para essa operação.

Não houve efeito significativo $(\mathrm{P}>0,05)$ do método de retirada da pele do filé sobre a resistência do couro à tração (alicate $=11,55 \mathrm{~N} / \mathrm{mm}^{2} ;$ máquina $=10,52 \mathrm{~N} / \mathrm{mm}^{2}$ ) e ao rasgamento progressivo (alicate $=20,53 \mathrm{~N} / \mathrm{mm}$; máquina $=$ $18,11 \mathrm{~N} / \mathrm{mm}$ ). Todavia, a remoção da pele do filé com uso de alicate influenciou os resultados do teste de alongamento do couro.

As peles retiradas com alicate apresentaram, após curtimento, menor flexibilidade ao alongamento, que foi signifi- 
cativamente superior para os couros retirados com máquina (alicate $=71,09 \%$; máquina $=88,48 \%$ ). Talvez a força empregada para remoção da pele tenha proporcionado maior estiramento das fibras colágenas, que, após o elevado estiramento, não apresentavam a mesma elasticidade de uma pele que ainda não tenha sido esticada.

Os couros curtidos com sais de cromo $\left(12,18 \mathrm{~N} / \mathrm{mm}^{2}\right.$, $93,08 \%$ e $25,54 \mathrm{~N} / \mathrm{mm}$ ) apresentaram resultados significativamente superiores aos curtidos sem sais de cromo $\left(9,89 \mathrm{~N} / \mathrm{mm}^{2}, 66,52 \%\right.$ e $13,11 \mathrm{~N} / \mathrm{mm}^{2}$, respectivamente para os testes de tração, alongamento e rasgamento progressivo) (Tabela 1).

No curtimento com sais de cromo, foram utilizados os óleos hidrofugantes da BASF, que proporcionam especial característica ao couro, aumentando a tensão superficial limite entre as fibras colágenas do couro e a água, pela envoltura das fibras com uma película hidrofugada (CATC - BASF, 1999), possibilitando aumento na resistência do couro. Nas peles curtidas sem sais de cromo, também foram utilizados os óleos hidrofugantes, todavia, o couro bioleather (sem sais de coromo) foi menos resistente aos testes de rasgamento, tração e alongamento (Tabela 1). Certamente, mesmo com essa proteção dos óleos hidrofugantes sobre as fibras colágenas das peles submetidas às duas técnicas de curtimento, houve ação de outros fatores, como os tipos de agentes curtentes utilizados na etapa de curtimento ou recurtimento, a combinação de produtos químicos, a concentração e o tempo de cada etapa do processo.

A carga de força aplicada até ruptura no teste de tração não apresentou diferença significativa entre os couros quando analisado o efeito dos métodos de retirada da pele e dos tipos de curtimento (com e sem sais de cromo) (Tabela 1).

De acordo com Souza et al. (2002), as peles de carpa espelho curtidas sem sais de cromo apresentaram resistência à tração de $18,75 \mathrm{~N} / \mathrm{mm}^{2}$, enquanto, nesse experimento, a resistência medida nas peles de tilápia foi de $9,89 \mathrm{~N} / \mathrm{mm}^{2}$.

Tabela 1 - Resultados do teste de resistência do couro de tilápia-do-nilo, de acordo com o método de retirada da pele do filé (alicate ou máquina) e com a técnica de curtimento (com ou sem sais de cromo)

Table 1 - Mean values of resistance test of Nile tilapia leather in function of the methods used in fillet removal (pliers and machine) and in tanning technique (chromium salts and bioleather)

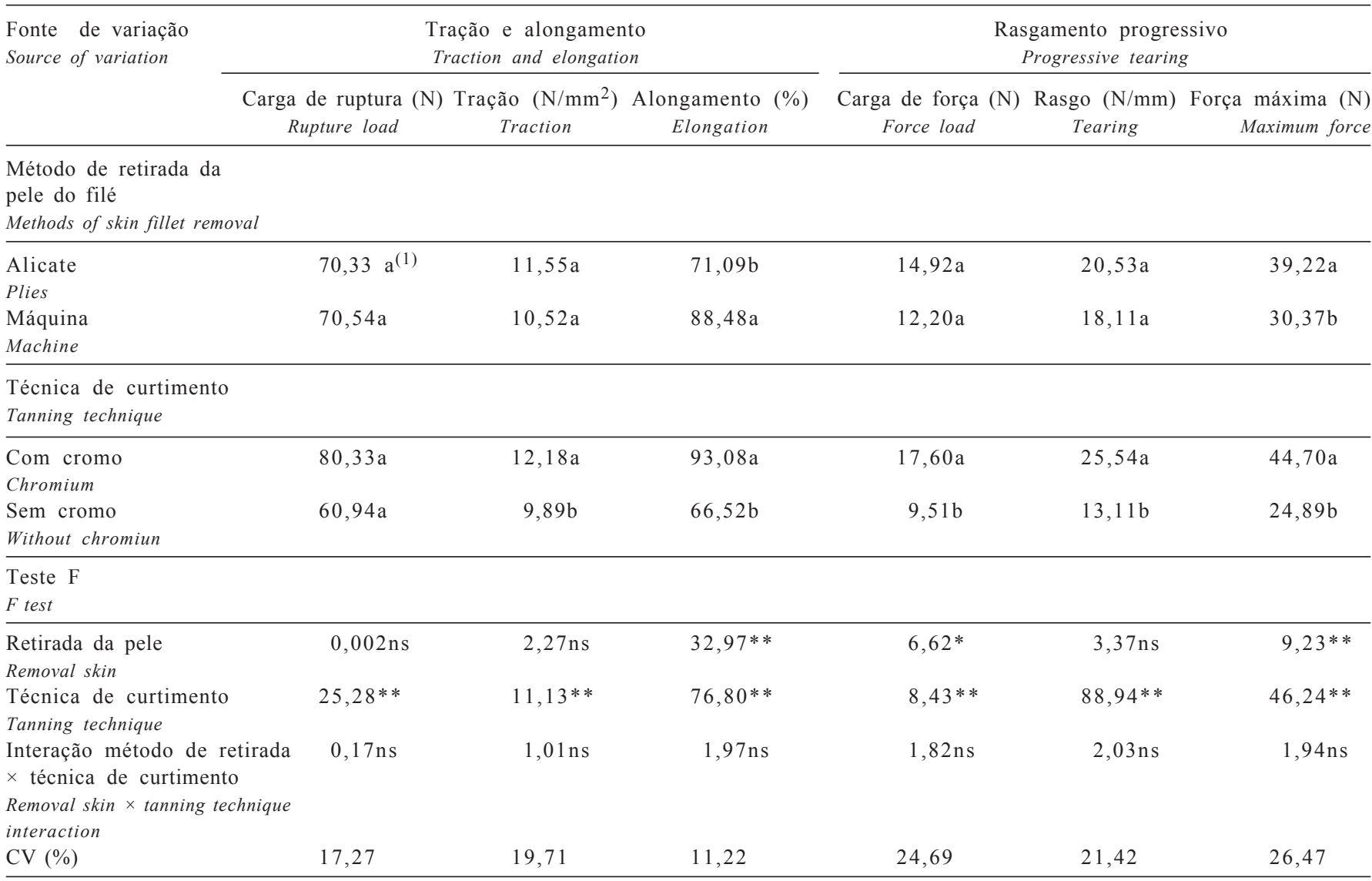

${ }^{1} \mathrm{Em}$ cada coluna, valores seguidos de mesma letra não diferem pelo teste Tukey a $5 \%$ de probabilidade.

1 Values followed by the same letter in a column do not differ by Tukey test at a $5 \%$ probability.

ns - não-significativo $(P>0,05)$; ** significativo $(P<0,01)$

$n s$ - not significant $(P>0.05) ;{ }^{*}$ significant $(P<0.01)$. 
Quanto ao teste de alongamento, o valor observado foi de $73,38 \%$, superior ao obtido para a tilápia $(66,52 \%)$, pela mesma técnica de curtimento, no sentido longitudinal do corpo-de-prova. A resistência ao rasgamento progressivo para o couro da tilápia-do-nilo com curtimento bioleather foi de 13,11 N/mm, superior à relatada por Souza et al. (2002) para pele de carpa espelho $(12,06 \mathrm{~N} / \mathrm{mm})$ curtida sem sais de cromo. A técnica sem sais de cromo utilizada neste experimento foi a mesma aplicada por Souza et al. (2002). Todavia, os resultados de resistência obtidos neste estudo, de $9,89 \mathrm{~N} / \mathrm{mm}^{2}$ para resistência à tração e $66,52 \%$ para resistência ao alongamento, foram diferentes dos relatados por Souza et al. (2002), de $18,75 \mathrm{~N} / \mathrm{mm}^{2}$ e $73,38 \%$, respectivamente, curtidos pela técnica sem sais de cromo. Esta diferença pode ser atribuída à espécie de peixe, que difere quanto à distribuição e orientação das fibras colágenas.

A carga de força e a força máxima aplicada na determinação da resistência ao rasgamento progressivo foi superior $(\mathrm{P}<0,01)$ nos couros curtidos com sais de cromo $(17,60$ e 44,70 N) quando comparados àqueles curtidos sem sais de cromo (couro bioleather) $(9,51$ e $24,89 \mathrm{~N}$, respectivamente, para a carga e força máxima aplicada no teste aplicada, a qual foi maior para as peles retiradas com alicate $-39,22 \mathrm{~N}$ ). A pele retirada com máquina, por apresentar maior elasticidade $(88,48 \%)$, necessitou de menor intensidade de força para o rasgamento progressivo. Todavia, isso também pode estar diretamente relacionando à espécie do peixe. Em trabalho semelhante, desenvolvido com a carpa espelho, não houve efeito do método de retirada da pele sobre a força máxima para rasgamento progressivo (Souza et al., 2002). A força máxima aplicada para a pele de carpa espelho retirada com máquina foi de $27,89 \mathrm{~N}$, enquanto para aquela retirada com alicate foi de $24,93 \mathrm{~N}$.

Portanto, a espécie de peixe está também diretamente relacionada aos resultados de resistência, provavelmente em relação à estrutura histológica da pele, pois as espessuras dos couros das duas espécies são próximas. Segundo Souza et al. (2002), a espessura da pele da carpa espelho variou de 0,70 a $0,76 \mathrm{~mm}$, enquanto a da tilápia, observada neste experimento, foi de 0,67 a $0,76 \mathrm{~mm}$.

Os couros curtidos sem sais de cromo, ou bioleather, apresentaram resistência à tração e ao alongamento superior à exigida para couro de bovinos curtidos com sais de cromo, destinados à confecção de vestuários, que são, no mínimo de $9,80 \mathrm{~N} / \mathrm{mm}^{2}, 60 \%$ e $14,72 \mathrm{~N} / \mathrm{mm}$, para resistência à tração, ao alongamento até a ruptura e ao rasgamento progressivo, respectivamente (Niveles de Calidad Aceptables en la Indústria del Cuero de Organización de las Naciones Unidas para el Desarrollo Industrial, 1976, relata- dos por Hoinacki, 1989). Todavia, as peles curtidas sem sais de cromo apresentaram valor inferior ao mínimo exigido apenas no teste do rasgamento progressivo $(13,11 \mathrm{~N} / \mathrm{mm})$. Portanto, quanto à resistência ao rasgamento progressivo são consideradas inadequadas para o uso na confecção de vestuário. Esse valor, no entanto, foi obtido no sentido longitudinal do couro e provavelmente seria diferente no sentido transversal, talvez superior, com média para ser utilizado na confecção de vestuário.

De acordo com Souza (2003), em pele de tilápia-do-nilo (de $500 \mathrm{a} 800 \mathrm{~g}$ ) submetida a sete diferentes técnicas de curtimento, os valores encontrados no teste de rasgamento progressivo variaram de 9,44 a $24,12 \mathrm{~N} / \mathrm{mm}$, conforme a técnica de curtimento aplicada. Esse autor avaliou os couros nos sentidos longitudinal e transversal ao comprimento do peixe. Os couros analisados para essa mesma variável apresentaram resistência significativamente menor no sentido longitudinal $(14,76 \mathrm{~N} / \mathrm{mm})$ em comparação ao transversal $(17,86 \mathrm{~N} / \mathrm{mm})$. Talvez, pela média (sentido longitudinal e transversal) no teste de rasgamento progressivo obtida em peles de tilápia curtidas sem sais de cromo, esse couro também atenda às condições exigidas para confecção de vestuários (comparados ao couro bovino curtido com sais de cromo).

Como não foram utilizados sais de cromo no curtimento do couro bioleather, não foi determinado o teor de óxido de cromo. A quantidade de óxido de cromo nos couros curtidos com sais de cromo foi de 3,78\% (Tabela 2).

O teor de óxido de cromo obtido na pele da tilápia-donilo está relacionado à proporção deste curtente fixado às fibras colágenas. Segundo Hoinacki (1989), o valor mínimo de óxido de cromo no couro semi-acabado deve ser de $3,0 \%$. A análise quantitativa de óxido de cromo do couro indicou capacidade para suportar elevadas temperaturas, sem retrair-se, fato comprovado pelo teste de fervura ou retração realizado durante o processo de curtimento.

A quantidade de substâncias extraíveis em diclorometano foi de $19,42 \%$ pela técnica com sais de cromo e de $20,02 \%$ pela técnica sem sais de cromo (bioleather). Entretanto, segundo Vademécum (1995), as substâncias extraíveis em diclorometano devem ser de, no máximo, 16 a 18\% para que o couro possa ser utilizado em vestuário. Souza et al. (2002) observaram, em peles de carpa espelho curtidas sem sais de cromo, valores de substâncias extraíveis em diclorometano de 13,78 a 15,76\%, inferiores aos encontrados neste experimento para os couros de tilápia-do-nilo.

$\mathrm{O} \mathrm{pH}$ das peles curtidas foi de 2,9 e 3,9 , enquanto os valores de cifra diferencial das duas técnicas foram 0,7 e 1,0, respectivamente, para peles curtidas com e sem sais de 
Tabela 2 - Teor de óxido de cromo, graxa, pH e cifra diferencial das amostras de couro de tilápia-do-nilo curtido com e sem sais de cromo (Bioleather)

Table 2 - Mean contents of chromium oxide $\mathrm{pH}$ and diferential cifra of Nile tilapia leather samples tanned with and without chromium salt (Bioleather)

Análise físico-química

Physical and chemical analysis
Técnica de curtimento

Tanning technique

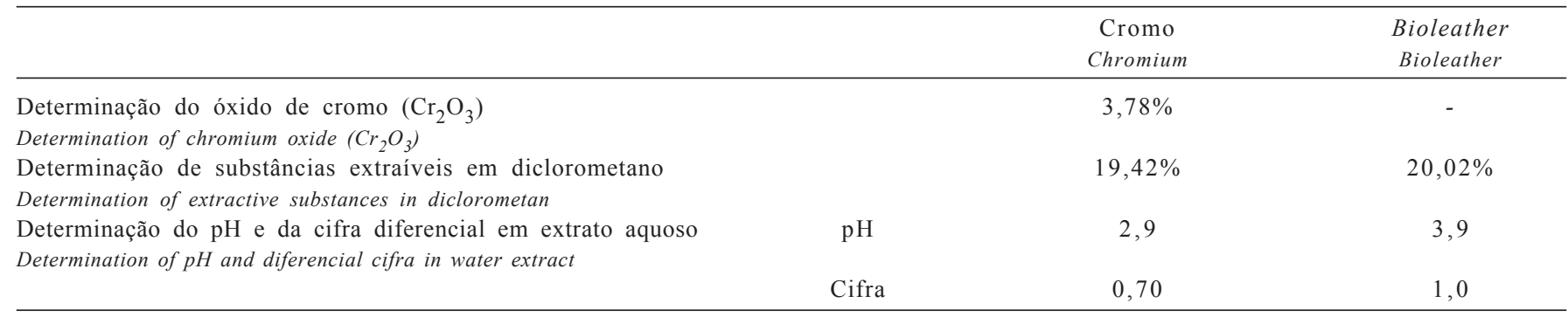

cromo (Tabela 2). De acordo com Hoinacki (1989), o valor mínimo de $\mathrm{pH}$ no couro semi-acabado deve ser de 3,5 e a cifra diferencial de, no máximo, 0,7. Para os couros de carpa espelho curtidos pela mesma técnica sem sais de cromo, Souza et al. (2002) encontraram valores de $\mathrm{pH}$ de 3,9 e cifra diferencial de 0,7 , ou seja, melhores que os obtidos neste experimento em peles de tilápia ( $\mathrm{pH} 3,9$ e cifra diferencial 1,0).

Considerando o pH do couro curtido ao cromo $(2,9)$, pode-se inferir que esse couro pode enfraquecer com o tempo de estocagem e uso. Portanto, a formulação utilizada deve ser modificada, reduzindo-se a quantidade de ácido aplicado no momento da fixação dos corantes e óleos de engraxe. A porcentagem de ácido na formulação do tingimento ao engraxe foi de $4 \%$ em relação ao peso das peles, o que deveria ser de aproximadamente $2,5 \%$ ou, no máximo, 3,0\% pela técnica com sais de cromo, conforme observado na formulação 1 .

As análises feitas nos couros de tilápia neste experimento foram sempre no sentido longitudinal, embora os valores relatados por alguns autores para o rasgamento progressivo sejam inferiores aos observados no sentido transversal. Talvez para análise mais apurada da resistência das técnicas de curtimento aplicadas, os testes de resistência deveriam ter sido realizados também no sentido transversal, possibilitando o valor médio entre ambos os sentidos (longitudinal e transversal).

\section{Conclusões}

A técnica de retirada da pele do peixe (com alicate ou máquina) não interferiu nas características de resistência do couro, exceto quanto à flexibilidade (alongamento), que foi maior para as peles retiradas mecanicamente (máquina).

A resistência ao rasgamento progressivo, à tração e ao alongamento foi superior nos couros curtidos com sais de cromo.
As peles curtidas com a técnica bioleather apresentaram resistência à tração e ao alongamento suficiente para utilização na confecção de vestuários em geral.

\section{Agradecimento}

À Secretaria Especial da Aqüicultura e Pesca da Presidência da República, pelo apoio na obtenção dos equipamentos do laboratório de curtimento. A José Telmo Agostini Schmidt, da Leather Solutions, e a Antonio Manuel Camim, pelo auxílio na execução do trabalho. À Epagri, à Empresa Cardume e à BASF, pelo inestimável apoio.

\section{Literatura Citada}

ASSOCIAÇÃO BRASILEIRA DE NORMAS TÉCNICAS - ABNT. NBR 10455: climatização de materiais usados na fabricação de calçados e correlatos. Rio de Janeiro: 1988. p.1-2.

ASSOCIAČ̃̃O BRASILEIRA DE NORMAS TÉCNICAS - ABNT. NBR 11030: couro - determinação de substâncias extraíveis com diclorometano $\left(\mathrm{CH}_{2} \mathrm{Cl}_{2}\right)$. Rio de Janeiro: 1997. p.1-3.

ASSOCIAÇÃO BRASILEIRA DE NORMAS TÉCNICAS - ABNT. NBR 11034: couro - preparação de amostras de couro para análise química. Rio de Janeiro, 2001. p.1-2.

ASSOCIAÇÃO BRASILEIRA DE NORMAS TÉCNICAS - ABNT NBR 11035: corte de corpos-de-prova em couro. Rio de Janeiro: 1990. p.1.

ASSOCIAÇÃO BRASILEIRA DE NORMAS TÉCNICAS - ABNT NBR 11041: couros - determinação da resistência à tração e alongamento. Rio de Janeiro: 1997. p.1-5.

ASSOCIAÇÃO BRASILEIRA DE NORMAS TÉCNICAS - ABNT. NBR 11054: couros - determinação de óxido crômico $\left(\mathrm{Cr}_{2} \mathrm{O}_{3}\right)$. Rio de Janeiro: 1999. p.1-5.

ASSOCIAÇÃO BRASILEIRA DE NORMAS TÉCNICAS - ABNT NBR 11055: couro - determinação da força de rasgamento progressivo. Rio de Janeiro: 1997. p.1-4.

ASSOCIAÇÃO BRASILEIRA DE NORMAS TÉCNICAS - ABNT NBR 11057: couro - determinação do $\mathrm{pH}$ e da cifra diferencial. Rio de Janeiro: 1999. p.1-3.

ASSOCIAÇÃO BRASILEIRA DE NORMAS TÉCNICAS - ABNT. NBR 11062: determinação da espessura. Rio de Janeiro, 1997. p.1.

BANZATTO, D.A.; KRONKA, S.N. Experimentação agrícola 3.ed. Jaboticabal: FUNEP, 1995. 247p.

CATC - BASF - Wet como ponto de partida para "couro ecológico". Revista do couro, n.237, p.32, 1999. 
GRAFFUNDER, V.; KOLLING, C.A. Resinas recurtentes: evolução e ecologia. Revista do Couro, n.154, p.34-38, 2002.

GUTTERRES, M. Considerações sobre curtimento ao cromo e meio ambiente. Revista do couro, n.122, p.28-29, 1997.

HOINACKI, E. Peles e couros: origens, defeitos, e industrialização. 2.ed.rev. Porto Alegre: Henrique d'Ávila Bertaso, 1989. 319p.

SOUZA, M.L.R. Processamento do filé e da pele da tilápia do Nilo (Oreochromis niloticus): aspectos tecnológicos, composição centesimal, rendimento, vida útil do filé defumado e testes de resistência da pele curtida. Jaboticabal: Universidade Estadual Paulista, 2003. 169p. Tese (Doutorado em Aqüicultura) - Universidade Estadual Paulista, 2003.

SOUZA, M.L.R. Tecnologia para processamento das peles de peixe. Maringá: Eduem, 2004. 59p. (Coleção Fundamentum, 11).

SOUZA, M.L.R; MACEDO-VIEGAS, E.M.; KRONKA, S.N. Influência do método de filetagem e categorias de peso sobre rendimento de carcaça, filé e pele da tilápia do Nilo (Oreochromis niloticus). Revista Brasileira de Zootecnia, v.28, n.1, p.1-6, 1999.
SOUZA, M.L.R; CASACA, J.M.; FERREIRA, I.C. et al. Análise da resistência do couro da carpa espelho curtido sem utilização de sais de cromo. Tecnicouro, v.23, n.8, p.57-69, 2002.

VADEMÉCUM para el técnico em curtición. 3.ed.rev. Ludwigshanfen: Basf, 1995. 477p.

Recebido: $17 / 02 / 05$

Aprovado: 30/01/06 